\title{
Pensando o Círculo Hermenêutico como um Caminho para a Pesquisa em
}

\author{
Psicologia \\ Ana Andréa Barbosa Maux* \\ Centro Universitário Facex - UNIFACEX, Natal, RN, Brasil \\ ORCID: http://orcid.org/0000-0003-1074-3572 \\ Elza Maria do Socorro Dutra** \\ Universidade Federal do Rio Grande do Norte - UFRN, Natal, RN, Brasil \\ ORCID: http://orcid.org/0000-0003-0225-9836
}

\begin{abstract}
RESUMO
Inspirado nas ideias apresentadas pelo filósofo Martin Heidegger, especificamente no círculo hermenêutico, este trabalho tem por objetivo pensar uma proposta de método para a pesquisa qualitativa em Psicologia. Parte da compreensão de método como sendo o caminho que desenha a rota percorrida pelo pesquisador e que vai acontecendo à medida que a pesquisa se desenvolve. $\mathrm{O}$ círculo hermenêutico heideggeriano descreve um processo que envolve um movimento circular compreensivo e serve de inspiração para a proposta de método apontada neste trabalho. A circularidade permite pensar o processo de pesquisar como sendo provisório, ao mesmo tempo que indica uma compreensão e uma interpretação contínuas, ininterruptas, portanto, inesgotáveis e características do existir humano. Numa tentativa de facilitar a compreensão, a proposta de método é apresentada de maneira didática, a partir dos conceitos de posição prévia, visão prévia e concepção prévia, cujo fim não é chegar a uma explicação ou verdade absoluta, mas ao desvelamento de sentidos, o que permite a compreensão do fenômeno estudado. Finaliza com o intuito de oferecer aos pesquisadores da área de ciências humanas uma possibilidade de se pensar um método que não dispense o rigor científico, mas que torne possível desvelar fenômenos relativos à existência.
\end{abstract}

Palavras-chave: método de pesquisa, pesquisa fenomenológica, círculo hermenêutico.

\section{Thinking of the Hermeneutic Circle as a Way to Psychological Research}

\begin{abstract}
Inspired by the ideas presented by the philosopher Martin Heidegger, specifically in the hermeneutic circle, this work aims to think about a method proposal for qualitative research in Psychology. The method being understood as the path that draws the route taken by the researcher and the research analysis process is going on throughout the research. The Heideggerian hermeneutic circle describes a process that involves circular movement and serves as inspiration for the proposed method of this work. The circularity allows us to think of the research process as being provisional and, at the same time, it indicates a continuous,
\end{abstract}

ISSN 1808-4281 
uninterrupted and inexhaustible understanding and interpretation which are characteristics of human existence. The method proposal is presented in this work in a didactic way from the concepts of prior perception, prior vision and prior conception, which purpose is not to arrive at an explanation or absolute truth, but to unveil meanings, which allows the comprehension of the studied phenomenon. It ends with the intention of offering researchers in the humanities area a possibility to think about a method of scientific rigor and that makes it possible to reveal phenomena related to existence.

Keywords: method, qualitative research, hermeneutic circle.

\title{
Pensando en el Círculo Hermenéutico como un Camino hacia la
}

\author{
Investigación Psicológica
}

\section{RESUMEN}

Inspirado en las ideas presentadas por el filósofo Martin Heidegger, específicamente en el círculo hermenéutico, este trabajo tiene como objetivo pensar en una propuesta de método para la investigación cualitativa en Psicología. Empieza con la comprensión del método como el camino que dibuja la ruta tomada por el investigador y que sucede a medida que la investigación se desarrolla. El círculo hermenéutico heideggeriano describe un proceso que involucra un movimiento circular de comprensión y sirve de inspiración para la propuesta de método señalado en este trabajo. La circularidad nos permite pensar que el proceso de investigación es provisional, al mismo tiempo que indica una comprensión y una interpretación continuas, ininterrumpida, por lo tanto, inagotables y características del existir humano. En un intento por facilitar la comprensión, la propuesta de método se presenta de una manera didáctica, basada en los conceptos de posición previa, visión previa y concepción previa, cuyo propósito no es llegar a una explicación o verdad absoluta, sino quitar el velo de los sentidos, lo que permite la comprensión del fenómeno estudiado. Concluye con el objetivo de ofrecer a los investigadores del área de humanidades la oportunidad de pensar en un método que no prescinda del rigor científico, pero que permita quitar el velo de los fenómenos relacionados con la existencia.

Palabras clave: método de investigación, investigación fenomenológica, círculo hermenéutico.

Nascido na região nordeste do país, o artesanato dos desenhos feitos com areia colorida em garrafas é uma arte que requer atenção e experiência por parte daquele que o constrói. Antes de iniciar a feitura de sua arte, o artesão precisa providenciar o material a ser utilizado, desde as diversas tonalidades de areia, até a garrafa que será usada para guardar a imagem a ser construída. 
Para o consumidor do artesanato, acompanhar toda a composição da obra faz a diferença, pois onde se vê, de início, materiais diversos, como areia de várias cores, palito, garrafa e cola, o artesão vislumbra um desenho. Ele e seu material de trabalho estão imbricados de tal forma que fica difícil olhar para o desenho pronto sem enxergar todo o fluxo desenvolvido em sua construção. A areia vai escorrendo pelas mãos hábeis do artesão e segue contínua para o interior do vidro, enquanto um palito vai contornando e proporcionando que as diversas cores se encontrem e, a partir dessa junção, formas sejam produzidas. Ele, o artesão, pode até ter uma ideia prévia do tema que irá construir, mas será pela experiência do encontro com o seu material de trabalho e com o comprador de sua arte que a mesma se dará.

É como o artesão dos desenhos feitos com areia colorida que pensamos a figura do pesquisador que se inspira na hermenêutica heideggeriana. Ele tem ideias iniciais, que definimos como sendo suas pré-concepções sobre o fenômeno a ser investigado. Mas é somente a partir do seu envolvimento com a pesquisa que ela se dará. É investigando ou, nas palavras de Critelli (2006), colocando em andamento as suas interrogações, que o pesquisador produz a sua arte.

Heidegger (1927/1999) concebe hermenêutica como sinônimo de interpretação, de sentido. Para o filósofo, todo desvelar o mundo é sempre interpretativo, pois parte de uma existência (ek-sistencia) e este é o modo-de-ser do homem.

Conforme palavras do próprio Heidegger (2001):

toda relação de pergunta e resposta move-se inevitável e constantemente em círculo. Só que não é um círculo vicioso, um círculo que deveria ser evitado por ser supostamente errado. Antes, o círculo pertence à essência de todo perguntar e responder. É possível que eu já tenha um conhecimento daquilo pelo que pergunto, mas isso não quer dizer que eu já reconheça explicitamente aquilo pelo que pergunto, reconhecer explicitamente no sentido de ter apreendido e determinado tematicamente. (Heidegger, 2001, pp. 64)

A pesquisa de fundamento fenomenológico hermenêutico é um trabalho artesanal e, assim, único. Não busca a verdade senão como Aletheia, ou seja, como desvelamento. Relacionando ao trabalho do artesão, podemos refletir que não basta a presença da areia colorida para que se possa encontrar um desenho, mas a manipulação desta, em suas várias cores, a textura do encontro com a mão do pesquisador, do palito e da garrafa, que faz com que o desenho vá se desvelando para um olhar. 
Nosso objetivo com este trabalho é pensar, a partir da construção de passos inspirados no círculo hermenêutico heideggeriano, uma proposta de método para a pesquisa qualitativa em Psicologia. Método é por nós considerado como o caminho que descreve a experiência de construção da pesquisa, que desenha a rota percorrida pelo pesquisador na feitura do seu ofício, à medida que a experiência acontece. Como o próprio filósofo afirma, "método significa o caminho no qual o caráter do campo a ser conhecido é aberto e limitado" (Heidegger, 2001, p. 132). Tal ideia se distancia da concepção de método na ciência moderna a qual, para o filósofo, seguiria uma noção de verdade que seria "o tipo de verdade estipulada pelo ego cogitum sum, isto é, pela subjetividade do "eu penso" no sentido da certeza" (Heidegger, 2001, p.133). Para o filósofo, este seria "o ataque mais monstruoso do homem à natureza, conduzido pela pretensão de ser "maître et possesseur de la nature"” (Heidegger, 2001, p. 133).

Tal ideia se aproxima do pensamento de Dilthey (2011) ao diferenciar as ciências naturais daquelas do espírito, uma vez que as primeiras teriam o objetivo de explicar os fenômenos, enquanto as ciências do espírito, de compreendê-los. Para esse filósofo, inclusive, tal diferença entre as ciências por ele distinguidas reside, primordialmente, na vida e diz que, “(...) e com isso, para a cisão crescente da vida em relação ao saber” (Dilthey, 2011, p. 32). A partir desse pensamento o filósofo sugere dois caminhos que poderiam ser trilhados pela Psicologia. Um deles seria adotar o método das ciências naturais; o outro seria assumir a ambiguidade dos fenômenos psíquicos sem apoio dos pressupostos científicos acerca da vida. Este seria o caso das pesquisas qualitativas, entre as quais encontram-se aquelas ditas fenomenológicas, de uma maneira geral.

Heidegger (2001) não apontou um modelo de método vislumbrando a pesquisa em Psicologia. Com isso, vale lembrar que a nossa proposta se inspira em suas ideias e no círculo compreensivo apresentado em sua analítica da existência e que serve como uma espécie de iluminação para a construção de um caminho possível para a pesquisa empírica numa ótica fenomenológico-existencial.

A sua definição de método, como mencionado antes, é a de um caminho que conduz a algo e que é marcado pela afetação que caracteriza a existência humana. Feijoo (2018) descreve método "como um lugar no qual o caminho da investigação copertence ao tema investigado por aquele que persegue o tema.” (p. 330). Em ambas as definições a figura do pesquisador já se faz presente e tem sua participação como uma das condições de base para que possamos conduzir a pesquisa. É a partir do olhar que ele vai lançar para o fenômeno que este encontrará abertura para o desvelamento. 
Antes de descrevermos uma possibilidade de caminho, consideramos necessário apresentar o material do qual é feito o solo que permitiu traçar essa possibilidade de rota: a fenomenologia hermenêutica.

\section{As Bases que Fundamentam o Nosso Olhar}

A Fenomenologia, surgida com Edmund Husserl, rompe com o modelo metafísico que pregava a verdade universal, ao propor a indissociabilidade entre sujeito e objeto. Esse pensamento explicita claramente a diferenciação com outras epistemologias. Para a Fenomenologia, a verdade é compreendida como um desvelamento de sentidos, como Aletheia. Nega a existência de uma verdade universal, pura e imutável, embasamento da perspectiva metafísica, contribuindo para a ciência por apresentar um modo de pensar e estudar os fenômenos da existência a partir do que a caracteriza: a provisoriedade e a relatividade da verdade.

Mas, enquanto a fenomenologia husserliana vislumbra a suspensão das ideias e conhecimentos prévios a respeito de um determinado fenômeno no intuito de apreender a sua essência, a proposta da hermenêutica heideggeriana acentua a ênfase no sentido construído na relação não fragmentada entre homem-mundo, pesquisador-pesquisado e fenômeno estudado.

Ainda que Heidegger tenha sido aluno de Husserl, o seu pensamento se distanciou das ideias do mestre, embora o princípio do "ir às coisas mesmas" tenha se mantido não apenas nas diversas correntes surgidas a partir de Husserl, mas também em sua fenomenologia, apesar das controvérsias existentes acerca desse distanciamento. Ir às coisas mesmas, princípio maior da fenomenologia, significa, segundo Stein (1983), que "cada espécie de ente tem seu modo próprio de se revelar ao investigador e, constatações filosóficas, para terem sentido, somente podem ser feitas quando fundadas nesta auto-revelação" (p. 33).

Stein (1983) é um dos mais importantes estudiosos da obra do filósofo alemão no Brasil. Ele afirma que Heidegger "desenvolveu um método fenomenológico próprio" (p. 30) dentro da corrente fenomenológica, desde Husserl. Para Stein (1983):

a ideia do mundo da vida é o elemento axial da obra de Heidegger e a base para a crítica a seu mestre e, simultaneamente, o elemento que ameaça toda a fenomenologia transcendental porque problematiza a radicalidade da redução na filosofia de Husserl. (Stein, 1983, pp. 44) 
Refletindo sobre o método no pensamento heideggeriano, Stein (1983) diz que:

A fenomenologia heideggeriana pretende ser um método que se situa nos antípodas da subjetividade, exigindo para isto o retorno ao fundamento da metafísica, tanto sob o ponto de vista do portador da metafísica, através da analítica existencial, quanto sob o ponto de vista da história da metafísica, através de um confronto sistemático-crítico com a História da Filosofia. Quer para a analítica existencial, quer para a superação da metafísica, Heidegger aplica o método fenomenológico, fundado num modelo binário: velamento-desvelamento. A aplicação do método fenomenológico a estas duas frentes visa pensar o ser que, na medida em que está velado, deve ser conduzido ao desvelamento. (Stein, 1983, pp. 21)

Ao encontro dessa visada seguem as palavras, categóricas, vale dizer, de Emanuel Carneiro Leão, na apresentação de Ser e tempo (Heidegger, 1927/ 1999), as quais reiteram o primado do velamento-desvelamento visto em Heidegger e que embasa, podemos dizer, um método que abrace a ideia de fugacidade do sentido, o que o torna inacessível a um método científico tradicional.

Assim diz Carneiro Leão (1999):

O ser sempre se esquiva e desvia em todos os desempenhos de apreendê-lo, em qualquer esforço por representá-lo e defini-lo. Pois tudo que fazemos ou deixamos de fazer serve para nos distanciar. E nunca terminamos de nos afastar. Pois não temos escolha. Fomos colhidos pela tração do retraimento. E na força desta tração, significamos o sentido do ser. Por isso, só nos resta encarar de frente o ser no movimento de seu sentido a fim de não perdê-lo de vista e esquecê-lo nas obnubilações do tempo. Os percalços e peripécias do tempo nos proporcionam o horizonte de doação do sentido que se dá, na medida em que se retrai (Carneiro Leão, 1999, pp. 14)

As ideias acima ressaltam alguns aspectos envolvidos numa pesquisa que se denomine fenomenológica hermenêutica, quais sejam, a certeza da impossibilidade de se alcançar uma verdade objetiva e absoluta, a certeza de que os sentidos alcançados serão sempre provisórios e o entendimento de que pesquisador-pesquisado encontram-se afetados pela sua condição de ser-no-mundo-com-outros. 
O próprio filósofo Heidegger (1927/1999), em Ser e tempo, discute o sentido do ser e diz considerar essa questão como fundamental, trazendo para isso a importância do questionamento. A seguir promove uma reflexão que nos parece oportuna e pertinente ao tema que discutimos neste texto e a proposta apresentada aqui, a qual situa-se no âmbito da pesquisa sob uma ótica fenomenológica hermenêutica. Diz o filósofo:

Todo questionamento é uma procura. Toda procura retira do procurado sua direção prévia. Questionar é procurar cientemente o ente naquilo que ele é e como ele é. A procura ciente pode transformar-se em "investigação" se o que se questiona for determinado de maneira libertadora. O questionamento enquanto "questionamento de alguma coisa" possui um questionado. Todo questionamento de...é, de algum modo, um interrogatório acerca de...Além do questionado, pertence ao questionamento um interrogado. (Heidegger, 1927/1999, pp. 30)

Continuando essa reflexão sobre o ser, Heidegger (1927/1999) completa o seu pensamento e com isso possibilita uma maior clareza sobre a ideia apresentada antes acerca do interrogado. Assim ele diz:

enquanto procura, o questionamento necessita de uma orientação prévia do procurado. Para isso, o sentido do ser já nos deve estar, de alguma maneira, disponível. Já se aludiu: nós nos movemos sempre numa compreensão do ser. É dela que brota a questão explícita do sentido do ser e a tendência para o seu conceito (Heidegger, 1927/1999, pp. 31)

Ou seja, podemos entender nessa fala a ideia do círculo hermenêutico proposto pelo filósofo e aqui vemos, podemos dizer, um momento de posição prévia, ou seja, se levarmos tal ideia para a pesquisa, quando elegemos um tema ou fenômeno a ser interrogado, previamente já temos uma visão do investigado, ou seja, já possuímos uma certa visão do ser, ainda que não saibamos o que é. A respeito do que diz o filósofo: "Nós não sabemos o que diz “ser". Mas já quando perguntamos o que é "ser" nós nos mantemos numa compreensão do “é”, sem que possamos fixar conceitualmente o que significa esse "é" (Heidegger, 1927/1999, p. 31).

Para Heidegger (1927/1999) todo desvelar o mundo é sempre interpretativo porque parte de uma existência e esta é o modo-de-ser do homem. A compreensão é uma estrutura 
essencial do existir humano (ou Dasein, para usar o termo heideggeriano), cuja característica é o de ser a abertura que permite que os fenômenos se desvelem, que lhe venham ao encontro. O homem somente se constitui a partir da constante relação com o mundo, com os outros e consigo mesmo, ou seja, a partir da sua existência concreta. Com isso, um trabalho que busque a compreensão da existência humana conforme a reconhecemos, deve contemplar o existir e essa relação indissociável.

O ser humano tem mundo. É sempre abertura (de sentido) a partir de onde as coisas podem aparecer. O filósofo alemão, além dessa característica de ser-no-mundo, descreveu outras que, para ele, eram próprias do ser humano e que o distinguia dos demais entes. A essas características, que ele definiu como existenciários, para fins de embasamento de um método de pesquisa, podemos considerar principalmente a facticidade, a disposição afetiva ou Befindlichkeit, a compreensão e a linguagem. Portanto, para realizarmos uma pesquisa que se diga hermenêutica, necessário se faz compreender como cada uma delas se mostra como uma espécie de alicerce que permite a elaboração de um caminhar na pesquisa.

A facticidade, conforme nos descreve Feijoo (2018), "se refere ao nosso existir em uma situação determinada. Como a estruturação do espaço existencial é temporal, o modo como cada homem existe é temporal.” (p. 332). Maux (2014) vai nos lembrar que a facticidade diz respeito ao mundo constituído por crenças, valores e regras que organizam a convivência e os modos de pensar de uma determinada sociedade em uma determinada cultura e descrito em um determinado período histórico. E existir vai justamente consistir na capacidade de projetar-se segundo as possibilidades que irão se apresentar como possíveis (e limitadas) por essa facticidade.

Compreender um fenômeno é, portanto, do ponto de vista hermenêutico, compreender o mundo. A partir da perspectiva de que o mostrar-se do fenômeno só é possível numa facticidade, compreendê-lo significa reconstruir o seu horizonte de mostração. "Todo e qualquer modo de lida com as coisas que nos vêm ao encontro já está previamente estabelecido pelo horizonte histórico de determinação de sentidos e significações." (Feijoo, 2018, p. 331).

Para Heidegger (1927/1999), existir é ser a abertura que permite que os fenômenos apareçam, sendo a disposição afetiva, ou humor, o jeito fundamental por meio do qual o Dasein se encontra e pode compreender o mundo. É como se, a partir de um estado de humor, cada um de nós imprimisse uma determinada iluminação ao que nos vem ao encontro, permitindo-nos enxergar determinado aspecto daquele fenômeno. Podemos traduzir a disposição afetiva ou Befindlichkeit como a atmosfera ou sentimento (Dutra, 2016; Gendlin, 
1978/1979) que envolve o Dasein em todas as situações em que se encontra e nas quais estão em jogo o seu ser. Na pesquisa não poderia ser diferente, pois a afetação, o humor ou sentimento estão presentes dando o tom ou a cadência do modo como a situação será vivida.

No círculo hermenêutico, a posição prévia, também chamada de pré-compreensão, é resultante da abertura do Dasein a partir da sua disposição afetiva. A partir desse humor o Dasein se relaciona com o que lhe vem ao encontro e, portanto, lhe atribui sentido. Isto implica elaborar um recorte remissivo de acordo com uma possibilidade determinada de interpretação. A isso dá-se o nome de visão prévia. A apreensão desses dois momentos diz respeito à concepção prévia e as três formam o "círculo hermenêutico" apresentado por Heidegger (1927/1999) em Ser e Tempo.

Produzir pesquisa a partir de um olhar hermenêutico ainda causa algumas desconfianças quanto a sua cientificidade. Isso porque a maneira de se fazer ciência apresentada pelas ciências naturais está tão presente em nosso cotidiano e nos é tão habitual, no que tange a pensar o fazer científico, que falar sobre o exercício pré-compreensivo que nos é característico parece-nos estranhos. Quanto a isso, o próprio filósofo apresenta um caminho possível para não se adotar inteiramente a perspectiva da ciência moderna e que pode ser pensado a propósito da pesquisa fenomenológica. Heidegger (2001) diz:

É necessário, principalmente, ganhar uma compreensão da singularidade da ciência moderna e manter em vista, incessantemente, o compreendido para pesar em sentido verdadeiramente crítico, isto é, diferenciando a objetivação científico-natural do mundo em confronto com o mostrar-se de fenômenos inteiramente diferentes que se opõem à objetivação científico-natural. (Heidegger, 2001, pp. 133)

E o filósofo segue nesse caminho para entender a ciência, e, ao invés de rejeitá-la, ele pensa que apenas devemos recusar a sua maneira absoluta de lidar com os fenômenos. Assim ele diz: "A ciência como tal não é rejeitada, de nenhuma maneira. Só a sua pretensão ao absoluto, a ser o parâmetro de todas as verdades, é julgada pretensiosa" (Heidegger, 2001, p. 136).

\section{Uma Possibilidade de Caminho}

Pesquisar a partir de uma inspiração fenomenológica hermenêutica requer mudança na concepção do que pode caracterizar o rigor científico tão propagado pelas ciências naturais, 
que tem modelos com limites definidos, vislumbrando controle, predição e rigidez no cumprimento de suas etapas. Sobre isso nos provoca Feijoo (2018):

Para investigar um tema em Psicologia, cada vez mais nos é exigida uma metodologia, totalmente definida em seus limites e em sua efetividade. Podemos, para alcançar a tal objetividade, proceder ao planejamento de nossas investigações por meio de três procedimentos que não contradizem em absoluto a ideia de objetividade e rigor. Para alcançarmos os nossos objetivos, utilizaremos o método fenomenológicohermenêutico, tal como utilizado por Heidegger, ou seja, reconstruindo, destruindo fenomenologicamente as verdades estabelecidas e construindo outras possibilidades de pensar o fenômeno em questão. (Feijoo, 2018, pp. 337)

Inspirando-nos nas ideias apresentadas pelo filósofo Heidegger e elaborando-as para a pesquisa, concebemos a circularidade conforme segue abaixo. Antes, porém, consideramos relevante ressaltar que a forma como será apresentada, de maneira sistemática, reflete tão somente o esforço de facilitar a compreensão e não de tecnologizar ou objetivar o processo apresentado.

A posição prévia diz das primeiras ideias que originaram ou instigaram o pesquisador sobre o fenômeno. Silva (2018) vai afirmar que a pesquisa se inicia com a interrogação que o pesquisador faz, sendo um convite ao estranhamento diante daquilo que se mostra. Então, a posição prévia diz respeito às ideias iniciais que o pesquisador traz. É posição, pois é de onde partem as suas inquietações sobre o fenômeno, incluindo-se aqui o conhecimento anterior sobre este, os preconceitos, as teorias e as afetações que o pesquisador carrega consigo acerca do fenômeno investigado.

Quando o pesquisador encaminha-se para ouvir as narrativas sobre o fenômeno, saindo da posição inicial e fazendo o movimento de ir ao encontro, isso requer dele o exercício de uma abertura dessa posição prévia, tornando-o a clareira na qual o fenômeno poderá se desvelar. $\mathrm{O}$ encontro com os colaboradores da pesquisa permitirá a elaboração de novos sentidos sobre o fenômeno. Aqui, temos a visão prévia. Neste estágio, já é possível iniciar recortes do fenômeno a partir daquilo que o pesquisador considera mais significativo, ou seja, no universo de possibilidades interpretativas possíveis, já se inicia uma delimitação destas possibilidades.

Referimo-nos a realizar encontro com narrativas pois nossa experiência tem sido com entrevistas que tenham essa característica. Os temas escolhidos para estudo em nosso grupo 
de pesquisa permitem que busquemos o acesso ao fenômeno não somente por material publicado, que de alguma forma, nos apresenta o horizonte histórico em que esse fenômeno se dá a conhecer, mas a partir de entrevistas com pessoas que, em sua existência, habitam de modo diferenciado o fenômeno estudado.

Conforme nos lembra Feijoo (2018):

Ao acompanhar fenomenologicamente o sentido que se encontra no âmbito de uma determinada experiência, precisamos, em um primeiro momento, recuar ante as interpretações da tradição, subtraindo a conotação moralizante do fenômeno em questão. E, assim, acompanhar os vetores internos mobilizadores da experiência, de modo que a dinâmica e a estrutura do próprio fenômeno se deem a conhecer. (Feijoo, 2018, pp. 331)

O encontrar-se com os colaboradores da pesquisa permite o movimento circular da visão prévia, pois retira o pesquisador da posição em que estava previamente e, ouvindo abertamente a experiência de outrem, movimenta-se para uma visão de novos horizontes e perspectivas.

Além de entrevistas, também consideramos o registro das afetações um recurso potente. Nele o pesquisador pode colocar em palavras, desenhos, símbolos, mapas, enfim, com algum registro gráfico, os sentidos apreendidos em cada momento de encontro. Nessa espécie de caderno de anotações, o registro segue um fluxo livre, sem roteiro ou modelo estabelecido de antemão. Ele é a expressão das afetações do pesquisador.

A concepção prévia diz respeito à apreensão deste conjunto de posição e visão prévias. É o momento no qual as articulações se juntam: o que se compreendia antes com o que se deu a conhecer a partir do encontro com o fenômeno. Trata-se dos sentidos possibilitados pela interpretação gerada a partir do encontro das ideias iniciais sobre o fenômeno estudado, os sentidos possibilitados pelo encontro com os colaboradores da pesquisa, bem como a partir do diálogo com a literatura.

Por fim, elabora-se um texto narrativo. A narrativa, na definição de Benjamin (1994) é uma forma artesanal de comunicação, que envolve o narrador e o fenômeno com o qual está em relação e que será o centro de sua narrativa. Esta não traz o fenômeno em sua totalidade ou essência, mas apresenta-o a partir das impressões do narrador, a partir de sua afetação. Como diz Dutra (2002), ao se adotar a narrativa na pesquisa estaremos adotando uma estratégia de natureza fenomenológica, uma vez que esta prioriza a experiência do narrador 
que, por sua vez, é transformada e ressignificada pela experiência do ouvinte. A narrativa traz a marca do narrador tal qual as paisagens de areia colorida estampam a assinatura do seu artesão.

A ideia de círculo remete a fluxo e, portanto, à compreensão de que o conhecimento não pode ser apreendido e encapsulado, tornando-se uma espécie de descoberta de caráter universal e definitivo ou permanente. Heidegger (1959) nos apresenta a ideia de pensamento meditante, que se caracteriza por ser aquele que reflete sobre o existir. Aquele que remete para além do que já é dado superficialmente e que leva à construção de novos sentidos a partir da reflexão, do processo de estar junto às coisas, habitando-as.

No processo de pensar, conforme o pensamento meditante, à medida que o homem se aproxima do seu existir, habita-o e, portanto, dá-se a conhecer. Assim, o sentido retorna para ele, ganhando uma nova compreensão, num círculo infinito que é, em si mesmo, a abertura. A proposta da circularidade permite pensar o processo de pesquisar como provisório, tendo em vista que diz respeito a um determinado momento existencial de afetação e, ao mesmo tempo, indica uma compreensão e uma interpretação contínuas, ininterruptas e, assim, inesgotáveis, que são características do existir humano.

Mas o pesquisador precisa dar a conhecer aos seus pares e à sociedade o que é o resultado de seu fazer. Assim como o artesão, a sua arte precisa ser divulgada para que possa ser vista, apreciada, atualizada e possa servir como inspiração para novas possibilidades de pesquisa daquele fenômeno.

A fase descrita como análise, em acordo com as reflexões trazidas por Heidegger (2001), é por nós pensada conforme descreve o filósofo, e diz do 'desfazer de uma trama em seus componentes', como também 'soltar', 'libertar'. Inclusive, ele opta pela palavra analítica para que não haja aproximação com o sentido usado pelas ciências naturais e que se refere a uma espécie de desmembramento do fenômeno (todo) em suas várias partes. Análise, assim como a concebemos, não diz de uma desintegração do fenômeno em vários pedaços que o compõem, mas diz de um poder "ver" do fenômeno para um determinado olhar: o olhar do pesquisador.

Os passos de análise iniciam no próprio processo de construção do tema a ser pesquisado, com a pré-compreensão. Desta feita, a análise acontece circularmente desde o início da pesquisa, e não como uma fase que ocorre seguidamente à coleta de material.

O texto narrativo construído ao final não representa apenas um relato da experiência descrita por aqueles que colaboram com a pesquisa a partir da contação de sua experiência em relação a determinado fenômeno. Ele é o resultado dos sentidos construídos pela figura do 
pesquisador a partir da experiência narrada e que se dá a partir da relação estabelecida entre ele e os colaboradores do estudo. Ele é um recorte remissivo das possibilidades interpretativas que se desvelaram na experiência de pesquisar.

\section{Considerações Finais}

O domínio das ciências naturais na sua condução do fazer científico transformou seu método em uma espécie de alternativa universal e inquestionável e a tendência dos pesquisadores e demais cientistas pode ser a de vislumbrar essa possibilidade de método como sendo a única e inquestionável maneira de se produzir ciência (Feijoo, 2018).

Nossa proposta com o presente trabalho foi somar esforços aos pesquisadores das ciências humanas, mais especificamente aos cientistas da psicologia que se identificam com a abordagem fenomenológico-hermenêutica e apresentar uma possibilidade de se pensar num método que não dispense o rigor científico, mas que torne possível desvelar fenômenos relativos à existência.

Concordamos com Maux (2014), quando destaca que a apropriação que fazemos das ideias filosóficas são possíveis e até incentivadas, posto que Husserl já vislumbrava uma psicologia fenomenológica e Heidegger (2001) demonstrava sua simpatia pelas práticas de cuidado, mencionando ser possível um diálogo entre Filosofia e Psicologia. A partir de reflexões sobre a daseinsanálise, o filósofo apresentou como possibilidade a apropriação de conceitos inicialmente filosóficos e sua aplicabilidade nas práticas da vida cotidiana que, por sua vez, reflete nas práticas clínicas psicológicas ou, no que foi aqui apresentado, em possibilidades de construção de pesquisa em Psicologia. Sobretudo, na mesma obra (Heidegger, 2001), o filósofo deixa claro o seu pensamento acerca do que poderia ser um método a ser adotado na pesquisa fenomenológica. Esse método consistiria, principalmente, em nossa relação com o que nos vem ao encontro "em que já nos encontramos sempre" (Heidegger, 2001, p. 136). Seria seguir o método na sua concepção original, como caminho. Mas um caminho em direção a nós mesmos, não apenas com a consciência de um ser-comoutro, mas sabendo ou na certeza de que não somos eus isolados, sozinhos e descolados do mundo. 


\section{Referências}

Benjamin, W. (1994). Obras escolhidas: Magia e Técnica, Arte e Política (7a ed.). São Paulo, SP: Brasiliense.

Carneiro Leão, E. (1999). Apresentação. In M. Heidegger, Ser e Tempo (8a ed., Vol. 1, pp. 722). Petrópolis, RJ: Vozes.

Critelli, D. M. (2006). Analítica do Sentido: Uma aproximação e interpretação do real de orientação fenomenológica (2a ed.), São Paulo, SP: Brasiliense.

Dilthey, W. (2011). Ideias sobre uma psicologia descritiva e analítica. (M. A. Casanova, Trad). Rio de Janeiro, RJ: Via Verita.

Dutra, E. (2002). A narrativa como técnica de pesquisa fenomenológica. Estudos de Psicologia, Natal, 7(2), 371-378. doi: 10.1590/S1413-294X2002000200018

Dutra, E. (2016). Rogers and Heidegger: Is a gathering for a new view of the self possible? Estudos de Psicologia, Campinas, 33(3), 413-423. doi: 10.1590/198202752016000300005

Feijoo, A. M. L. C. de. (2018). Metà-hodós: Da fenomenologia hermenêutica à psicologia. Revista da Abordagem Gestáltica, 24(3), 329-339. doi: 10.18065/RAG.2018v24n3.7

Gendlin, E. (1978/1979). Befindlichkeit: Heidegger and the philosophy of Psychology. Journal of Existential Psychology and Psychiatry, 16(1-3), 43-71. Recuperado de http://previous.focusing.org/gendlin/docs/gol_2147.html

Heidegger, M. (1999). Ser e Tempo (8a ed., Vol. 1). Petrópolis, RJ: Vozes. (Obra original publicada em 1927)

Heidegger, M. (1959). Serenidade. Lisboa, Portugal: Instituto Piaget.

Heidegger, M. (2001). Seminários de Zollikon. Petrópolis, RJ: Vozes.

Maux, A. A. B. (2014). Masculinidade à prova: Um estudo de inspiração fenomenológicohermenêutico sobre a infertilidade masculina (Tese de Doutorado). Universidade Federal do Rio Grande do Norte, Natal, RN, Brasil. Recuperado de https://repositorio.ufrn.br/jspui/handle/123456789/17403

Silva, E. F. G. (2018). Pesquisa qualitativa em psicologia clínica: Uma possibilidade metodológica em diálogo com a fenomenologia hermenêutica. Revista Pesquisa Qualitativa, 6(11), 145-159. doi: 10.33361/RPQ.2018.v.6.n.11.176

Stein, E. (1983). A questão do método na filosofia: Um estudo do modelo heideggeriano. Porto Alegre, RS: Movimento. 


\section{Endereço para correspondência}

\section{Ana Andréa Barbosa Maux}

Rua Desembargador. Virgílio Dantas, 740, Barro Vermelho, Natal - RN, Brasil. CEP 59020-560

Endereço eletrônico: anabmaux@gmail.com

\section{Elza Maria do Socorro Dutra}

Rua Professor Olavo Montenegro, 2887, Capim Macio, Natal - RN, Brasil. CEP 59078-330

Endereço eletrônico: elzadutra.rn@gmail.com

Recebido em: 02/07/2020

Aceito em: 06/09/2020

\section{Notas}

* Psicóloga, graduada pela Universidade Federal do Rio Grande do Norte, doutora pela Universidade Federal do Rio Grande do Norte, professora do Centro Universitário Facex.

** Psicóloga, Pós-doutora pela Universidade Federal Fluminense, professora do Programa de Pós-graduação em Psicologia da Universidade Federal do Rio Grande do Norte.

Este artigo de revista Estudos e Pesquisas em Psicologia é licenciado sob uma Licença Creative Commons Atribuição-Não Comercial 3.0 Não Adaptada. 